\title{
BLOOD LACTATE RESPONSE DURING MODERATE EXERCISE IN NEUROCIRCULATORY ASTHENIA, ANXIETY NEUROSIS, OR EFFORT SYNDROME ${ }^{1}$
}

\author{
By MANDEL E. COHEN, FRANK CONSOLAZIO, AND ROBERT E. JOHNSON
}

(From the Medical and Psychiatric Clinics and Cardiac Research Laboratory of the Massachusetts General Hospital; the Departments of Medicine and Diseases of the Nervous System, Harvard Medical School; and the Fatigue Laboratory, Harvard Graduate School of Business Administration)

(Received for publication November 23, 1946)

\section{INTRODUCTION}

It has been amply demonstrated that the concentration of blood lactate rises during moderate exercises (1). It was therefore of interest to study the response of blood lactate in men with neurocirculatory asthenia (N.C.A.), anxiety neurosis, or effort syndrome to a standard amount of moderate exercise. Studies have been made on blood lactate response in patients with effort syndrome (2). In those studies, however, the patients exercised a lesser amount than did the control subjects, thereby rendering the blood lactate results difficult of interpretation. Two types of work experiments must be differentiated. The first is that in which the patient is asked to perform until exhaustion. In this type of experiment, it is of interest that one subject may perform longer than another. Physiologic data from this type of study are difficult to compare with those of control subjects since time of exercise is not comparable $(3,4)$. This type of experiment is subject to considerations of the subjects' willingness to perform, "true ability" to perform, persistence, and similar factors which are as yet difficult to quantitate.

Another type of work experiment is the moderate exercise test. The task is set at a level where the work can be finished both by the patient and the control subject. This study reports tests of this second kind. By using a standard amount of work which both the patient and control subject finish it is possible to compare response of one group of patients with a control group.

1 The work described in this paper was done under a contract recommended by the Committee on Medical Research, between the Office of Scientific Research and Development and the Massachusetts General Hospital. Responsible Investigators: Paul D. White and Stanley Cobb.

\section{METHOD}

Patients selected were men in the armed forces in whom a diagnosis of neurocirculatory asthenia had been made (5). Forty-two patients with chronic neurocirculatory asthenia and 19 patients with acute neurocirculatory asthenia were studied, along with 41 healthy control subjects. On grounds of history alone, two groups of patients were differentiated. Those who had a lifelong course of the condition or who could never do hard work or athletics were designated "chronic neurocirculatory asthenia," while those who gave convincing evidence of good health, ability to do muscular work or athletics, and nervous stability previous to the onset of the illness were designated "acute neurocirculatory asthenia." The control subjects were soldiers who had been through basic training and were in a good state of health. These studies were done as part of a general study of work in neurocirculatory asthenia. A half-hour rest period is followed by a 15minute walk on a treadmill, which is set at 3.5 miles per hour, and 8.9 per cent grade. The work output in this test is 1.17 large calories per kilo and hour (81.90 large calories per hour for a 70-kilo man). Specimens of finger blood are collected during the ninth minute of the walk, blood being taken from the finger of the dependent hand into a heparinized watch glass. Care is taken to avoid contaminating the blood with alcohol or any other substance which might interfere with the accurate estimation of blood lactate. The determinations were done in duplicate for lactate concentration by the method of Edwards (6). The values recorded here are the mean for duplicate determinations which checked within 3 milligrams. In some cases respiratory studies (ventilation and $\mathrm{O}_{2}$ consumption) were done from the ninth to the fourteenth minute of the walk. The walk is concluded at the end of 15 minutes. Patient is given a short rest and then allowed to run on the treadmill to exhaustion. The results of the run will not be reported on or discussed in detail in this paper (7).

\section{RESULTS}

All patients reported here finished the full walk. Results of blood lactate concentration determinations in the patients are presented in Figure 1 which shows that patients' average is higher than 


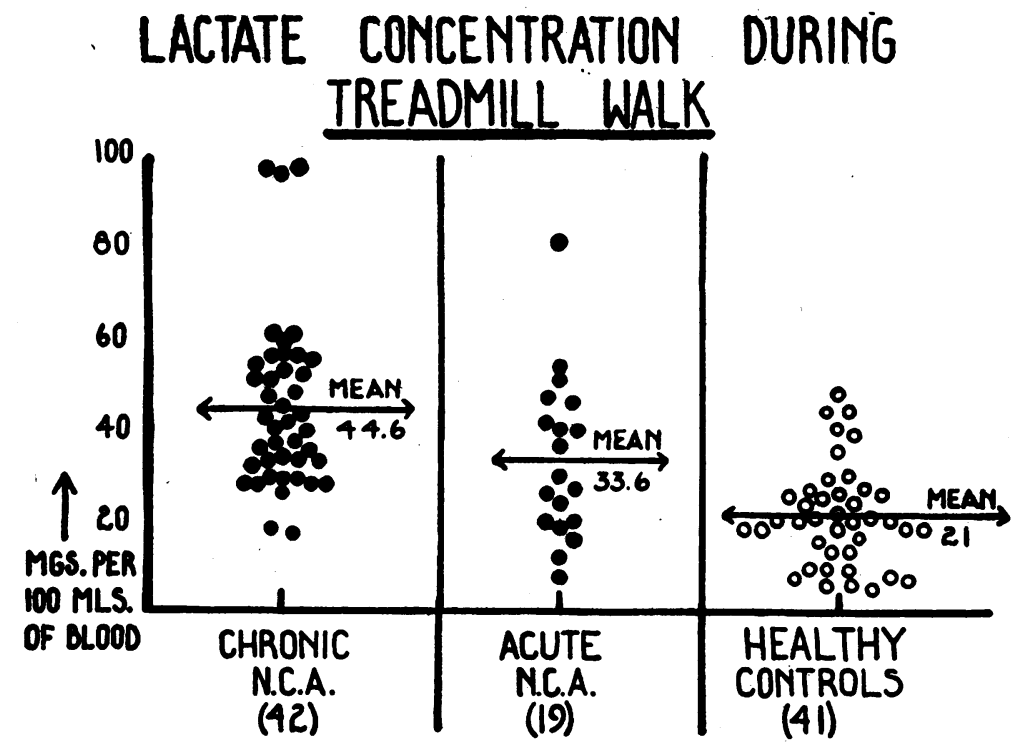

Fig. 1. Data for Blood Lactate Concentration During Treadmill WALK

Each dot or circle represents average of duplicate determinations from first test in each subject. The patients show significantly higher blood lactate concentration as compared with controls. The chronic N.C.A. patients show significantly higher levels of blood lactate concentration as compared with acute N.C.A.

that of healthy control subjects. The men with acute neurocirculatory asthenia do not average so

TABLE I

Summary of averages, statistical calculations, and significances of differences in lactate results in walking

\begin{tabular}{|c|c|c|c|}
\hline & $\begin{array}{l}\text { Healthy } \\
\text { control } \\
\text { subjects }\end{array}$ & $\begin{array}{l}\text { Acute } \\
\text { N.C.A. }\end{array}$ & $\begin{array}{l}\text { Chronic } \\
\text { N.C.A. }\end{array}$ \\
\hline $\begin{array}{l}\text { Number of cases } \\
\text { Mean } \\
\text { Coefficient of variation } \\
\text { Standard deviation } \\
\text { Standard error } \\
\text { Standard error of the difference } \\
\text { between means: } \\
\text { Healthy } \\
\text { Acutes } \\
\text { Chronics } \\
\text { Significance ratio: Difference of } \\
\text { means/standard error of } \\
\text { the difference between } \\
\text { means: } \\
\text { Healthy } \\
\text { Acutes } \\
\text { Chronics }\end{array}$ & $\begin{array}{c}41 \\
21.3 \\
.51 \\
10.86 \\
1.70\end{array}$ & $\begin{array}{r}19 \\
33.6 \\
.53 \\
17.86 \\
4.10 \\
\\
4.44 \\
5.00\end{array}$ & $\begin{array}{r}42 \\
44.6 \\
.42 \\
18.52 \\
2.86 \\
\\
\\
3.32 \\
5.00\end{array}$ \\
\hline
\end{tabular}

Odds against the occurrence of a deviation as great or greater than the designated number of Standard Errors:

Healthy to acutes - 180 to 1 . Acutes to chronics-35 to 1 . Chronics to healthy-400,000,000,000 to 1 . high as do the men with chronic neurocirculatory asthenia. The differences between these groups are statistically significant as is shown in Table $\mathrm{I}$. The mean blood lactate concentration for all. 61 N.C.A. patients is $41.2 \mathrm{mgm}$. per $100 \mathrm{ml}$. of blood. This differs markedly from the controls with a significance ratio of the difference being 7.02 .

Table II shows the resting blood lactate values along with the values obtained during walking for each subject. The resting values for the controls and the patients are the same despite the fact that the walking values are higher for the patients.

There is no correlation in individual cases between resting and walking values of blood lactate concentration in N.C.A. or controls (Correlation Coefficients, chronic N.C.A., .25; healthy, .18).

Table III shows that replicate determinations, from successive walk studies in patients with N.C.A., give consistent results, the difference in means of the two groups being less than one mgm. per $100 \mathrm{ml}$. of blood. 
TABLE II

Lactate concentration-mgm. per $100 \mathrm{ml}$. of blood

\begin{tabular}{|c|c|c|c|c|c|c|c|c|}
\hline \multicolumn{3}{|c|}{ Chronic N.C.A. } & \multicolumn{3}{|c|}{ Acute N.C.A. } & \multicolumn{3}{|c|}{ Healthy controls } \\
\hline Case & $\begin{array}{c}\text { Rest- } \\
\text { ing }\end{array}$ & $\begin{array}{c}\text { Walk- } \\
\text { ing }\end{array}$ & Case & $\begin{array}{c}\text { Rest- } \\
\text { ing }\end{array}$ & $\underset{\text { ing }}{\text { Walk- }}$ & Case & $\begin{array}{c}\text { Rest- } \\
\text { ing }\end{array}$ & $\begin{array}{c}\text { Walk- } \\
\text { ing }\end{array}$ \\
\hline $\begin{array}{r}3 \\
5 \\
7 \\
11 \\
13 \\
14 \\
18 \\
21 \\
22 \\
23 \\
24 \\
25 \\
28 \\
30 \\
31 \\
32 \\
33 \\
34 \\
38 \\
39 \\
40 \\
41 \\
44 \\
45 \\
46 \\
49 \\
52 \\
55 \\
58 \\
61 \\
63 \\
65 \\
67 \\
68 \\
70 \\
71 \\
73 \\
74 \\
80 \\
86 \\
87 \\
89\end{array}$ & $\begin{array}{r}14 \\
18 \\
16 \\
18 \\
8 \\
18 \\
26 \\
16 \\
12 \\
24 \\
10 \\
\frac{1}{18} \\
12 \\
14 \\
19 \\
14 \\
15 \\
9 \\
13 \\
30 \\
\frac{1}{11} \\
\frac{16}{93} \\
23 \\
13 \\
14 \\
45 \\
13 \\
13\end{array}$ & 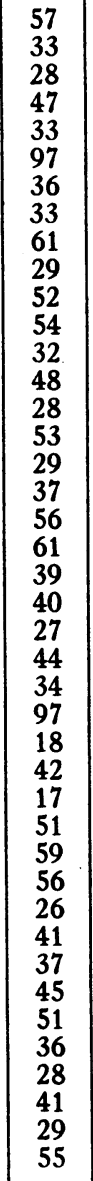 & $\begin{array}{l}201 \\
204 \\
206 \\
207 \\
213 \\
215 \\
216 \\
217 \\
221 \\
223 \\
224 \\
225 \\
230 \\
231 \\
238 \\
239 \\
240 \\
241 \\
248\end{array}$ & $\begin{array}{r}20 \\
19 \\
10 \\
11 \\
12 \\
18 \\
18 \\
22 \\
11 \\
12 \\
12 \\
16 \\
10 \\
9 \\
13 \\
11 \\
12 \\
9\end{array}$ & $\begin{array}{r}40 \\
41 \\
47 \\
16 \\
12 \\
27 \\
37 \\
24 \\
30 \\
8 \\
51 \\
26 \\
39 \\
19 \\
81 \\
40 \\
54 \\
20 \\
20\end{array}$ & $\begin{array}{l}401 \\
406 \\
407 \\
410 \\
411 \\
416 \\
417 \\
418 \\
422 \\
424 \\
430 \\
435 \\
436 \\
438 \\
439 \\
440 \\
442 \\
445 \\
447 \\
448 \\
450 \\
451 \\
452 \\
455 \\
490 \\
491 \\
492 \\
493 \\
494 \\
495 \\
496 \\
497 \\
498 \\
499 \\
500 \\
501 \\
502 \\
503 \\
504 \\
505 \\
506\end{array}$ & $\begin{array}{l}13 \\
10 \\
15 \\
19 \\
20 \\
14 \\
15 \\
18 \\
19 \\
14 \\
10 \\
26 \\
20 \\
16 \\
13 \\
9 \\
19 \\
21 \\
13 \\
14 \\
11 \\
22 \\
= \\
= \\
= \\
= \\
- \\
- \\
- \\
-\end{array}$ & $\begin{array}{r}27 \\
20 \\
16 \\
44 \\
30 \\
20 \\
44 \\
26 \\
20 \\
18 \\
39 \\
25 \\
40 \\
24 \\
19 \\
24 \\
26 \\
48 \\
26 \\
20 \\
29 \\
18 \\
18 \\
18 \\
6 \\
8 \\
7 \\
9 \\
5 \\
9 \\
21 \\
21 \\
35 \\
7 \\
6 \\
9 \\
22 \\
15 \\
13 \\
13 \\
27\end{array}$ \\
\hline $\begin{array}{l}\mathbf{N} \\
\text { Mean }\end{array}$ & $\begin{array}{l}32 \\
11.8\end{array}$ & $\begin{array}{l}42 \\
44.6\end{array}$ & & $\begin{array}{l}18 \\
13.9\end{array}$ & $\begin{array}{l}19 \\
33.6\end{array}$ & & $\begin{array}{l}23 \\
16.2\end{array}$ & $\begin{array}{l}41 \\
21.3\end{array}$ \\
\hline
\end{tabular}

\section{DISCUSSION AND SPECULATION}

These data show that during standard moderate exercise blood lactate concentration in patients is greater than that of healthy control soldiers. Similarly, poorly trained subjects (8), normal women (9), and elderly men (1) show high blood lactate concentration during treadmill walking. These patients had spent some time in the hospital and were not in active training. Most of them had been through basic training in service. Whether these results merely reflect poor state of training cannot be ascertained from these data.
TABLE III

Blood lactate during successive walks on different days in patients with neurocirculatory asthenia

\begin{tabular}{c|c|c|c}
\hline \hline \multirow{2}{*}{ Case } & First walk & Second walk & Difference \\
\cline { 2 - 3 } 21 & \multicolumn{2}{|c|}{ mgm. per 100 ml. of blood } & \\
\cline { 2 - 3 } 28 & 33.0 & 41.0 & 8.0 \\
34 & 32.2 & 31.0 & -5.5 \\
40 & 37.0 & 29.0 & -8.0 \\
44 & 39.0 & 36.0 & -3.0 \\
48 & 27.0 & 30.0 & 3.0 \\
63 & 17.0 & 11.0 & -6.0 \\
73 & 59.0 & 87.0 & 28.0 \\
74 & 51.0 & 50.0 & -1.0 \\
206 & 36.0 & 30.0 & -6.0 \\
207 & 47.0 & 37.0 & -10.0 \\
223 & 16.0 & 20.0 & 4.0 \\
238 & 8.0 & 24.0 & 16.2 \\
No. & 107.0 & 76.0 & -31.0 \\
Mean & 13 & 13 & 13 \\
& 39.2 & 38.6 & -0.9 \\
\hline
\end{tabular}

An attempt to train some of these men was unsuccessful as the men did not train properly (4). This left open the question as to whether training would bring this abnormality in blood lactate concentration to normal levels. Methyl testosterone, administered because of similarities in some aspects of the physiology of N.C.A. with that of women and older men, did not increase physical fitness test scores in N.C.A., nor did intravenous administration of cytochrome. $C$ change the blood lactate concentration during walk significantly (7). These data do not tell whether the high blood lactate in N.C.A. during walking is due to increased formation, increased blood concentration, abnormal rate of destruction, or removal from blood.

The abnormality in blood lactate concentration during moderate work shows a clear cut difference betwen N.C.A. and healthy control subjects. It suggests that N.C.A. patients have special difficulties in doing muscular work and fits well with patients' constantly reiterated statements that they are unable to keep up in muscular work with other men.

In discussing their lactic studies, Jones and Scarisbrick (10) concluded that the patients "show very poor response to exercise as judged by the amount of work done. At the same time, however, there is no major biochemical abnormality in their response. The $\mathrm{pH}$ and lactate were in keeping with the amount of work done, though we have ocasionally seen a case where the rise of 
lactate and $\mathrm{pH}$. shift is excessive for a small output of work." This inspired a medical editorial which stated (11), "The patients' bodily response to exercise does not differ in any discoverable respect from that of other subjects of their own age. ... The level of lactic acid reached in these experiments lent no support to the view that patients with effort syndrome behave otherwise in physiologic respects to other people."

Our data are in direct contradiction to these statements. It is true, to be sure, that if N.C.A. patients perform for a shorter time than do controls their blood lactate concentration may be lower. This was true in our studies of severe work where patients ran for a shorter time (4). However, for the same duration and amount of muscular work, whether moderate or severe (4, $7,12)$, blood lactate concentration is high in N.C.A. The lower level at "exhaustion" and the higher levels for the same amount and duration of muscular work confuse some readers and may seemingly offer a contradiction. The seeming contradiction is due to the fact that in severe muscular work N.C.A. patients reach the stopping point earlier than do controls; but, for the same amount and duration of effort, blood lactate concentration is higher in N.C.A. This demonstrates that, if the patients' difficulty is, as was stated (10), simply a matter of lack of "persistence," this lack of persistence is usually associated with a chemical abnormality-that is, increased blood lactate concentration.

The exact explanation for this is not at hand. Taken with our evidence of low oxygen consumption in N.C.A. during running $(7,12)$, it suggests deficient aerobic metabolism and excessive oxygen debt. It is noteworthy that cytochrome C did not correct the high blood lactate during walking in N.C.A. We have no data which explain completely the exact mechanism of this abnormality in neurocirculatory asthenia.

\section{CONCLUSIONS}

1. Blood lactate concentration is significantly higher in neurocirculatory asthenia during moderate exercise than in controls.
2. The abnormality is greater in chronic N.C.A than in acute N.C.A.

3. It cannot be stated whether state of training or other factors account for the difference.

4. A chemical abnormality has been demonstrated in neurocirculatory asthenia which fits well with patients' statements that they cannot keep up with other men in muscular work.

\section{BIBLIOGRAPHY}

1. Robinson, S., Experimental studies of physical fitness in relation to age. Arbeitsphysiol., 1938, 10, 251.

2. Jones M., and Scarisbrick, R., Effort intolerance in soldiers; review of 500 cases. War Med., 1942, 2, 901.

3. Joknson, R. E., Brouha, L., and Darling, R. C., A test for physical fitness for strenuous exertion. Revue Canadienne de Biologie, 1944, 1, 491.

4. Cohen, M. E., Johnson, R. E., Cobb, S., Chapman, W. P., and White, P. D., Studies of work and discomfort in patients with N.C.A. J. Clin. Invest., 1944, 23, 934.

5. White, P. D., Cobb, S., Chapman, W. P., Cohen, M. E. and Badal, D. W., Observations on N.C.A. Tr. A. Am. Phys., 1944, 58, 129.

6. Edwards, $H$. T., A simplified estimation of lactate in normal human blood. J. Biol. Chem., 1938, 125, 571.

7. Cohen, M. E., Johnson, R. E., Chapman, W. P., Badal, D. W., Cobb, S., and White, P. D., A study of neurocirculatory asthenia, anxiety neurosis or effort syndrome. Final Report to the Committee on Medical Research of the Office of Scientific Research and Development under contract OEM-cmr157, 1946.

8. Edwards, H. T., Brouha, L., and Johnson, R. E., Effets de l'entrainement sur le taux de l'acide lactique sanguin au cours du travail musculaire. Travail Humain, 1940, 8, 1.

9. Metheny, E., Brouha, L., Johnson, R. E., and Forbes, W. H., Some physiologic responses of women and men to moderate and strenuous exercise. A comparative study. Am. J. Physiol., 1942, 137, 318.

10. Jones, M. S., and Scarisbrick, R., Effect of exercise on soldiers with effort intolerance. Lancet, 1943, 245, 331.

11. Annotation on the biochemistry of effort syndrome. Lancet, 1943, 245, 329.

12. Cohen, M. E., Johnson, R. E., Consolazio, F., and White, P. D., Low oxygen consumption and low ventilatory efficiency during exhausting work in patients with neurocirculatory asthenia, effort syndrome, anxiety neurosis. J. Clin. Invest., 1947, 26, 920 . 